DOI: https://doi.org/10.47405/mjssh.v6i4.738

\begin{tabular}{|c|c|}
\hline 4 & Malaysian Journal of Social Sciences and Humanities (MJSSH) \\
\hline $\begin{array}{l}\text { Malaysian Journa of } \\
\text { Social cciences and }\end{array}$ & Volume 6, Issue 4, April 2021 \\
\hline (MJ-sSH) & e-ISSN : 2504-8562 \\
\hline & $\begin{array}{l}\text { Journal home page: } \\
\text { www.msocialsciences.com }\end{array}$ \\
\hline
\end{tabular}

\title{
Smart Learning Improves Student Participation
}

\author{
Lee Bih Ni ${ }^{1}$, Chai Wan Luen ${ }^{1}$, Sopiah Abdullah ${ }^{1}$ \\ ${ }^{1}$ Faculty of Psychology and Education, Universiti Malaysia Sabah (UMS) \\ Correspondence: Lee Bih Ni (leebihni@ums.edu.my)
}

\begin{abstract}
This paper discusses smart learning improves student participation. The transmission of COVID-19 affects the lives of everyone in Malaysia. Many hope that life will return to normal. The objective of the study was to identify several ways of online learning for students especially stay at home due to the Covid-19 pandemic. Researchers use narrative literature studies to illustrate the current state of art and science in the field of research focused. Researchers used narrative literature reviews to build a scientific base of knowledge. Researchers gather all the key points in the discussion, and put it here by referring to the specific field where the paper is essentially based. The findings show that the parents certainly require their children to be able to resume school after closed since mid-March 2020 which affect the learning process of 4.9 million students nationwide. The Ministry of Education (MOE) learning activities are still running as usual with teachers advised to find the best method. These are students who strive to learn remotely online and use electronic equipment (e-learning). The reality is the e-learning situation is very different from the daily school routine.
\end{abstract}

Keywords: Various frameworks of learning, Applications (m-DOA)

\section{Introduction}

Malaysia is experiencing a deficit in local content production, particularly due to the dumping of digital content abroad, especially from the West. Digital content includes video, games, software applications and animation. According to the Malaysian Digital Economy Corporation (MDEC) website, local digital content production earned RM7.9 billion for national revenue for 2017. Digital content sales reached RM1.42 billion with 11,590 job opportunities created. During the Movement Control Order (MCO), Education TV was not able to accommodate the online learning of local students whether Science, Technology, Engineering and Mathematics (STEM) based subjects or vice versa. Various frameworks of learning methods and adaptations are implemented. One of them is through the mobile learning framework of Design, Opportunities and Applications (m-DOA). One of the smart approaches to $\mathrm{m}-\mathrm{DOA}$ is constructive learning based on experience. Through it, lecturers are seen as facilitators, while the production of learning content is empowered by students themselves as digital content developers. This process includes constructive learning through active experience, reflection on the task, abstract conceptualization of the task associated with the learning principles as well as new theories and strategies to be applied. A smart learning environment also refers to a learning ecology that practices interconnected communication through mobile learning, with the use of mobile hardware and devices; social awareness through the use of social media for communication in maintaining the sustainability of smart learning and seamless network connectivity through wireless network connectivity. Among the functions of smart learning is to complete daily tasks and activities that have 
added value to life. It can inject beneficial added value to daily work and activities. Smart learning fosters meaningful life values for activities - whether for leisure, personal use, or to perform tasks related to the user's daily activities. For example, students can use smartphones to improve personal skills such as learning new skills and compiling daily personal activity schedules. In turn, it can improve knowledge and management of daily work tasks. One of the advantages of using a smartphone is its multimedia functionality. There is great potential for learning because all university students in Malaysia have smartphones. Students can use multimedia functions on smartphones such as video recording, audio and photography as well as for personal daily use. Lots of smart educational opportunities through mobile learning. Most students use smartphones to make multimedia digital recordings and complete their assignments such as on farms, science laboratories or archeological sites (Shamsul, 2016).

One of the uses of smartphones for educational purposes is through the 'bring your own device' (BYOD) approach which can reduce the cost of purchasing mobile hardware to learn. A smart learning approach through hardware and smartphone devices can empower student activities through a given trust. Creative and innovative learning activities provide positive benefits to the development of local digital multimedia content. Students can collaborate, be active and motivated and have more fun engaging through digital multimedia content development activities. Through smart learning methods, students better understand the subject being taught. This is reflected in the improvement of student performance through the digital development of quality multimedia content. Thus, the support of the government and non-governmental organizations (NGOs) is important to provide ecological infrastructure for smart learning such as the provision of hardware, devices, training, infrastructure and local digital content, which can be owned by local people. In conclusion, the generation of student activities through mobile hardware is recommended to be further developed as one of the approaches to create new jobs especially for young people, besides reducing the problem of lack of local digital content (Shamsul, 2016).

\section{Literature Review}

Many students, teachers and parents are still struggling with e-learning methods. As it is not yet clear when students can return to school, the implementation of e-learning needs to be improved to be more systematic and inclusive. First, low device ownership makes the implementation of e-learning quite challenging. The results of the MOE survey involving almost 900,000 students showed a number or 37 percent has no device. Only six percent of students have a personal computer; tablets (9 percent) and smartphones (46 percent). Even if some families own the device, most still need to share it with other family members for work or study purposes. Initiatives to increase device ownership need to be implemented. These include granting device purchase grants, creating device loan schemes such as textbook loan schemes and providing free devices to students from low-income families. While this measure requires government financial allocation, it is a worthwhile investment for the future of the country. Private companies and non-governmental organizations (NGOs) can mobilize efforts to donate new or used computers to be distributed to schools. Additionally, tax relief can be extended to encourage device ownership. It is appropriate for device purchase expenses and internet charges to be categorized separately from other lifestyle expenses as per the current tax relief schedule. The amount of tax relief can be increased as the cost of these two items is quite high. Second, a smooth internet connection is very important for the e-learning process to be effective. Although mobile broadband penetration is high at 120 percent, fixed line broadband penetration speeds are higher and stable at only about eight percent. Internet access still has many constraints in terms of coverage and speed due to lack of fiber optic network. Efforts to implement the National Optical Fiber and Connectivity Plan (NFCP) need to be redoubled so that high-speed and affordable internet access can be enjoyed by the community (Hawati, 2020).

The government's initiative to provide $1 \mathrm{~GB}$ of free mobile data is not enough to support class teleconferencing and video display activities due to high data requirements. Students from poor families are unable to purchase additional data more often due to financial constraints. Telecommunication companies should consider providing free additional data to assist teachers, 
parents and students. Third, since the rate of smartphone ownership among students is quite high, the medium is used by teachers to deliver lessons through WhatsApp or Telegram messages. However, the delivery of teaching and learning via smartphones needs to be enhanced. Appropriate rules need to be practiced to ensure more systematic and effective communication. Teachers can act as administrators to monitor the communication activities of group members and only important messages should be allowed to facilitate all information taken action. Fourth, teaching and learning activities should be uniform, including learning and homework for all subjects. Nowadays, the learning process depends a lot on the initiative and ability of teachers to use e-learning. This needs to be improved and teachers need to strive to adhere to the syllabus and implement teaching and learning consistently and systematically. Fifth, television, radio and video streaming channels should be fully utilized as an alternative method of delivering lessons to large groups of students. EduwebTV, for example, was created by KPM to provide online education services. However, video streaming usually uses high data. Alternatively, KPM launches Education TV Program or Class @ Home but this program only runs for two hours every day. Broadcast time needs to be extended to cover more subjects and for each level (degrees and levels). Subjects which need less visual assistance such as history can be taught through radio as it is still an important medium of communication of information. Sixth, although elearning is ongoing, direct interaction between teachers and students is still limited due to the high number of students per class. The effectiveness of e-learning can be enhanced by hiring teacher assistants / tutors among new graduates to participate in student guidance programs, thus addressing youth unemployment. Tutors can be assigned to smaller groups of students to give more specific attention. However, students who are less fortunate and have special needs should not be forgotten. Thus, students with disabilities, underprivileged and low-performing are given priority to return to school when COVID-19 can be controlled and MCO relaxed (Hawati, 2020).

Current learning challenges need to be addressed as they can affect long-term life prospects and social mobility. Losing a source of family income can increase the dropout rate of school students. Prolonged economic stress can also adversely affect a child's physical and mental health through the influence of parents' mental health. The effects of the crisis can also be felt by students after the situation recovers. Studies in some countries have found that youths entering the labour market after the global financial crisis face a higher probability of getting low-paying jobs, longer unemployment and enjoying slower career advances than when economic conditions were more stable. Although there are no similar studies in Malaysia, the current social mobility trend is quite alarming. A study by Khazanah Research Institute (KRI) found that although the current generation generally has a higher standard of living, social mobility is seen to be slowing down due to weakening economic growth, higher competition in the labour market and education premiums, especially from declining higher education. Efforts to redouble the use of technology and bridge the digital divide between all walks of life need to be done immediately. Otherwise, the long-term effects will widen the gap of inequality and cause more children to drop out (Hawati, 2020).

\section{Maxis Explores Digital Gaming Industry Opportunities}

Maxis Bhd explores business potential in the digital gaming industry by expanding its services, product offerings and package development to support the development of the industry ecosystem in Malaysia. Its Head of Brand and Marketing, Tai Kam Leong, said Maxis strengthened its presence in the market by offering three high-performance mobile devices for digital games packaged with Maxis Zerolution, in-game purchases through billing operators for Maxis, Hotlink and Ookyo customers. He said, although the latest data states that more than 40 percent of young people between the ages of 16 and 24 in Malaysia are digital game enthusiasts, but the digital game industry is much larger covering all ages, mobile devices, consuls and home fiber networks. For the future, Maxis expect there is great business potential for this industry to be explored as a telecommunications company. In fact, Maxis collaboration with Team Secret provides an opportunity for companies to enrich their customer experience with digital sports (eSport) content. Maxis also play an important role in shaping the Malaysian digital gaming ecosystem by meeting the needs of consumers through future Maxis products. Team Secret is the eSport Malaysia professional team for PUBG Mobile games to the International level. Through the collaboration, both parties will develop exclusive world-class digital game content for a year to produce more local digital game enthusiasts representing the country to the 
world eSport arena. Meanwhile, the company's current focus was on offering mobile digital games and related services through the three smartphone devices it offered. However, Maxis also saw the opportunity to explore the residential segment through the fiber optic network by expanding service support across mobile games to the segment (Che Wan, 2019).

\section{MOJO Nurtures Creative, Innovative Content}

Media practitioners need to be faster and agile in channeling the latest news and information to the community without compromising the ethics of journalism. All media practitioners can record and deliver news, but reporting must support journalism ethics and a responsible attitude towards the country. The method of direct reporting through certain devices including mobile phones is seen as a new mechanism to the world of news today. News approaches and methods like this should be commended and should be practiced continuously by media agencies. The minister said at a seminar on Mobile Journalism (MOJO) - Digital News in Your Hands in the ministry on 28 April 2020. What makes MOJO attractive and its priority is its ability to deliver fast, close delivery, overcome obstacles, be controllable and can be deployed quickly. The use of smartphones encourages creative content across platforms and digital innovation as it is used to record, edit and produce photos, videos, audio and graphic images. Materials can be uploaded immediately to websites and various social media platforms for the purpose of conveying information to the people. Journalists will acquire new knowledge and skills such as podcasts and photography without expensive equipment. Smartphones with certain applications are like a production studio in the hands of journalists. Therefore, the media agencies to re-map the direction of work as a planned collaboration so that it can double the direct impact by triggering a wave of information, including those that touch on government policy so that the people know quickly (Mohd Nasaruddin, 2019).

\section{Samsung, LG Introduce Virtual Reality Smartphones}

The warm-up of the Mobile World Congress (WMC) in Barcelona is now underway and meeting expectations, the virtual reality (VR) platform is gaining momentum at most of the world's leading mobile brand manufacturers. The growing trend of consumer interest and the shift in the need to use digital content through VR, has successfully influenced the development of the global market despite the fact that the technology has been on the market for almost 10 years. The opening of a week-long global mobile device industry event starting today saw several global electronics firms begin launching their VR devices. Samsung Electronics and LG began introducing new smartphone devices with improved cameras and the ability to display VR displays for use with their VR headsets.

The move is seen as a two-pronged move for companies to raise consumer interest and improve sales amid a slowdown in demand for mobile devices. Samsung launched two versions of the smartphone, the Galaxy S7 with a flat screen and the Galaxy S7 edge, with a curved screen. Both new smart devices are developed with cameras capable of recording in low light environments. At the same event, the South Korean electronics giant also introduced the Gear 360, a small spherical camera with a tripod, capable of recording 360 degrees around the user simultaneously. The move to introduce devices and viewing headsets along with cameras recording VR content before the launch of MWC 2016 is Samsung's attempt to further strengthen its position ahead of Apple. The camera, which is specially designed to capture photos and videos around the user, can be downloaded to Facebook and YouTube, or better enjoyed through Samsung's VR headset, Gear VR, which will begin marketing in November 2016. Facebook CEO and Founder Mark Zuckerberg also held a surprise press conference at Samsung to announce a collaboration with the Korean Technology Firm to promote the use of VR on its social media sites. At the same event, LG also shared Samsung's position by introducing its new premium device, the G5, the first modular phone to use different components, allowing users to upgrade independently, covering all key components of the phone, including the battery. The G5 is offered with accessories such as sound systems developed by Bang \& Olufsen and VR headsets that allow it to compete in the same market league as Samsung's VR headsets last year (Che Wan, 2016). 


\section{Online Lectures To Avoid Infection}

When the World Health Organization (WHO) declared COVID-19 as a pandemic and Malaysia received the second wave of the epidemic which recorded a total of 428 cases, local universities began directing the implementation of teaching and learning online. Several methods can be taken into account depending on the methodology and content of teaching in their respective fields. Technology MARA University (UiTM) developed i-Learn portal to improve education quality. It improves education effectiveness and conventional teaching techniques. It provides an opportunity for lecturers to create web-based teaching content and online learning activities.

For universities with a total of 175,200 students nationwide with 12 state campuses (seven are autonomous state campuses); satellite campus in Shah Alam (6); state satellite campus (11) and allied colleges (21), UiTM embarked on an initiative to introduce e-learning starting in 2005 . It also constantly improves the education portal and the solution shows the importance of creating other alternatives in the teaching and learning process. With the internet accessibility in the country, the spread of the COVID-19 epidemic should not interfere with the teaching and learning process in institutions of higher learning. In addition to the official e-learning portals developed by some universities, lecturers can use portals on existing platforms or websites such as Zoom, Google Suite and Google Classroom. Google Meet, a video conferencing platform and application integrated into the Google Suite. However, if some lecturers find the platform above a bit complicated, Live Facebook, WhatsApp Business and Skype video conferencing are the options available. Critical and creative thinking in such situations helps us face this pandemic more maturely (Noor Ayuni, 2020).

Other more advanced options are like Microsoft Team, which is a virtual communication and collaboration communication platform for a certain period of time involving live instruction, video on syllabus content, workspace file storage and other application integration. For lecturers who have been involved in e-learning methodology for a long time, the online teaching and learning implementation instructions from the university management provide the opportunity to make full use of the previously developed teaching content through Screencast-O-Matic. It is a Java-based web application that can be used to produce short videos recorded with the voice of the user or individual to produce the learning content and at the same time, display all movements on the monitor display. Admittedly, not all learning content and syllabus meet the teaching and learning methodology online as recommended by university management. For example, laboratories, fieldwork, workshops, studios, field activities or kitchen work. As a precautionary measure, several implementation procedures are outlined by the university management. For any presentation involving face to face with large groups, they are recommended to be broken down into smaller groups. They also need to ensure a safe distance of one meter and comply with the safety and health measures outlined by the Ministry of Health Malaysia $(\mathrm{MOH})$ and the Health Center of their respective universities. It is also emphasized that student supervision activities should be ensured within one meter. Institutions of higher learning are areas where many people gather almost every day. It is hoped that the alternative online teaching and learning session will be able to curb the spread of the COVID-19 epidemic among university residents without affecting the education sector itself. The cooperation of various parties including the Ministry of Higher Education and the top management of the university which provides flexibility as well as lecturers and students are very much needed (Noor Ayuni, 2020).

\section{Parliament: Ministry Of Education Malaysia Detected 763 Schools Have Covid-19 Cases}

A total of 763 schools nationwide recorded cases of COVID-19 infection among its citizens as of 20 November 2020. Senior Minister (Education), said the record may not be complete as there were some positive cases not reported to the ministry. Through monitoring at schools, we find that the number of infections increases when there are clusters in the workplace involving parents and children at risk of being infected. He said this at the winding up session of the Supply Bill (RUU) 2021 policy level for the Ministry of Education (MOE) in the Dewan Rakyat, 23 November 2020 (Radzi, 2020). MOE is aware that the closure of the school at this time somewhat hinders the access of Teaching and Learning (T\&L) to students, but the ministry continues to work to ensure that access is met. 
MOE are actively ensuring that methods can be implemented so that learning activities can be continued so that these children get an education. MOE always mention online learning methods, but not all our children have access to the internet and devices and that is why we use various methods including Educational TV and delivery of learning materials to students. MOE also introduced the method of Teaching and Learning at Home covering Teaching and Learning for optimal learning at home. Apart from that, MOE provided the DELIMa (Digital Educational Learning Initiative Malaysia) learning platform and 485 digital textbooks have been uploaded through the system, to help students who do not have internet access and suitable devices, teachers take the initiative to implement Teaching and Learning through the delivery of learning materials to students. Teachers assess students continuously as well as plan interventions based on the suitability of students. The instructions for all schools operated by MOE remain closed until the last day of year 2020 school session (Radzi, 2020).

\section{Methodology}

This research method used literature review, which included new insights into the quality of action and scientific papers. The literature review activity began with four steps: 1) developing questions; 2) searching the literature; 3) data evaluation; 4) analysis and interpretation. All steps are performed in stages. Analytical techniques are performed in the following ways: 1) Compare (find the equation); 2) Contrast (discovering inequality); 3) Criticism (giving opinions); 4) Synthesis (comparative); 5) Summary.

\section{Findings \& Discussion}

Factors of internet access and gadget ownership are seen to be among the main factors causing the Teaching and Learning at Home (TLH) process to be less effective. President of the National Union of Teaching Professions Malaysia (NUTP), said it contributed to some negative effects and complicated the situation of the low-income group. Apart from that, the NUTP survey found that 93 percent of teachers chose the TLH method face to face despite admitting that they were satisfied with the cooperation given by parents to make TLH a success. Teachers' skills in handling TLH are improving and each of them already has experience during the implementation of MCO, March last year. Admittedly, teachers face challenges and difficulties in conducting TLH for Year One students because students have never undergone such a process before. However, NUTP cannot reject TLH because it is the only method available when the country is facing the COVID-19 pandemic. The Ministry of Education (MOE) reported that face-to-face school sessions starting January 20 throughout the country are limited to the main examination candidates for 2020 .

In this regard, only Malaysian Certificate of Education, Malaysian Vocational Certificate (SVM), Malaysian Skills Certificate (SKM) and Malaysian Higher School Certificate (STPM) 2020 examination examinations, need to go to school to follow face-to-face learning. Also listed are students who will sit for the Malaysia Higher Certificate in Religious (STAM) and Malaysian Vocational Diploma (DVM) 2020 examinations as well as equivalent international examinations. Students might face the problem of dropout in the education system when only relying on TLH, it may result in the development of students with disabilities. It cannot be a measure of the effectiveness of producing a balanced human capital. "In this case, it cannot be compared and all parties must accept the situation of TLH is based on the readiness of students, apart from the teaching objectives of teachers are limited and need to be diversified according to creativity. When the situation returns to normal, maybe teachers can take other steps to repair the problem during the implementation of TLH. Meanwhile, NUTP Secretary-General suggested that the government provide tax exemption for the purchase of devices, as well as focus on mobilizing non-governmental organizations (NGOs) and the private sector for the provision of conducive infrastructure. NUTP have received radical feedback and suggestions for TLH to be held outside working hours (to ensure students' focus while studying), but it needs to be agreed by all parties (Muhammad Yusri, 2021). 


\section{Teachers Need To Master Digital Technology To Meet The Demands Of Teaching And Learning}

If in the past, telecommunication devices such as smartphones and gadgets were prohibited from being brought to school. Now, the opposite happens when the world of education needs to be accessed online and classes can be implemented in any place with internet access. The global crisis due to the spread of the COVID-19 epidemic not only caused the face-to-face to be delayed, but also made teachers' tasks more challenging when they had to adapt to new habits. It demands that the teaching and learning process be implemented online using the various applications available. Examples are WhatApps, Zoom and Cisco Webex. Taking into account the current educational context, it requires teachers to have a level of communication and information technology (ICT) literacy (Ong Yao Ping, 2020).

Themed 'Teaching for Knowledge, Build a New Generation' year 2020's Teacher's Day celebration touched on the role of teachers in empowering knowledge and professionalism to build a new generation and useful human capital to develop a more peaceful and prosperous country in the future. During the period of the Movement Control Order (MCO) which started on March 18, before being extended to several phases until now entering the implementation of the Recovery Movement Control Order (RMCO), teachers did not sit still. Instead, they continue to pour knowledge through online teaching and learning. Therefore, teachers need to deepen their knowledge of new technologies by using more effective ways to communicate with students. President of the Malaysian Muslim Teachers Association (i-Teacher), opined that educators, especially teachers, need to equip themselves with various knowledge on mastery in new digital technologies and master knowledge related to e-learning to make it easier to deliver knowledge to students. This readiness will be seen to change in terms of teaching, assessment and delivery of knowledge that challenges the teaching task. The most important thing is that we need to ensure that students do not lose the spirit to gain knowledge and teachers also do not lose the spirit to impart knowledge. To all teachers in Malaysia, despite the cheers and cheers of students and students celebrating Teacher's Day at school this time, the appreciation to appreciate the sacrifices of teachers in educating, guiding and shaping the nation must always be ingrained in everyone's heart. The service of human beings with the title of educator is huge and everyone realizes the fact that the presence of a teacher in life greatly shapes a person's personality and skills to be a useful human being (Ong Yao Ping, 2020).

\section{The New MaxisONE Prime Came With Unlimited Data}

Maxis Bhd launched the new MaxisONE Prime (MOP) which is equipped with unlimited data for mobile phones as well as home fiber broadband. MaxisONE plans start from RM98 per month and any residential fiber plan of their choice starts from just RM89 per month. The new plan offers unlimited data for all family members and enables the combination of any MaxisONE Plan and residential fiber plan. MaxisONE Prime was introduced in conjunction with fibrenation campaign with the most affordable fiber broadband plan. Customers can enjoy unlimited internet for each family member and faster speeds (Sri Ayu, 2018). This also demonstrated Maxis leadership in comprehensive offerings, and permanent and mobile connectivity solutions available to more Malaysians in a statement. For a limited time, MaxisONE Prime customers will also enjoy discounts of up to 50 percent on various luxury devices and more at Zerolution360, when they sign up for MOP128 and above. Customers can also enjoy unlimited internet for mobile phones and homes, no matter the combination of plans they choose, family members will get unlimited data for their mobile phones and homes. The shared line which now costs RM48 will also enjoy unlimited data (Sri Ayu, 2018).

\section{COVID-19: Maxis Records The Use Of Additional Data In History}

Maxis Bhd recorded the highest data usage in history during the implementation of the Movement Control Order (MCO) following the transmission of COVID-19. Maxis said in a statement that the company's monitoring found that residential fiber traffic and daily mobile data volume had increased significantly since the start of MCO on March 18, with the number of mobile phones continuing to grow. There was also an increase in voice call traffic on the first day of MCO, although it returned to 
normal to the trend before MCO. Meanwhile, Maxis Chief Technology and Information Officer said internet browsing, video streaming and instant messaging were among the major contributors to the increase in data traffic, with mobile devices mostly used for browsing activities (Mohd Zaky, 2020).

In addition the increase in the amount of data for streaming applications for Residential Internet can also be seen. For example, YouTube usage recorded the highest amount of data for Maxis, with an increase of more than a few thousand TeraBytes $(1 \mathrm{~TB}=1,024 \mathrm{~GB})$. Instant messaging and voice over IP (VoIP) has increased by about 50 percent along with collaboration tools such as Microsoft Teams, Skype and Google Hangouts. It is most likely contributed by those who study and work from home. It is very clear that our users use a lot of data, and especially in these challenging times. As a result, it is very important for our customers to get a good Internet experience for their daily needs. Maxis increased site production by 100 percent and accelerated the implementation of capacity in meeting growing demand. Continuous network optimization to complete the implementation of the network can ensure that customers will enjoy a quality experience, especially for commonly used applications. About 800 frontline employees serving customers in-store as well as field technicians to ensure the network remains active, and we are very grateful for their dedication (Mohd Zaky, 2020).

\section{Maxis, Sarawak Multimedia Authority (SMA) Collaborates In IoT Initiatives}

Maxis Bhd signed a memorandum of understanding (MoU) with the Sarawak Multimedia Authority (SMA) to implement joint ventures in the Internet Object Object (IoT) Initiative and the Narrow Broadband Internet Object (NB-IoT) Initiative. In a statement, Maxis said the collaboration would focus on developing expertise and sharing of experience and knowledge in IoT and NB-IoT concept solution applications, while at the same time strengthening the partnership chain in the design, development and implementation of IoT and NB-IoT solutions. Both parties will also develop a strong ecosystem through the support of laboratory establishment and expert support to develop sustainable and intelligent solutions. The communications service provider welcomed SMA's efforts in helping drive the state's digital economy agenda by recognizing the urgent need to accelerate digital technology in most industries (Bernama, 2019).

Maxis remains committed to being a strong partner of the government through leadership in networking, digital services and communications solutions. Maxis want to play an important role in delivering NB-IoT services and solutions, especially to key sectors of the country such as agriculture and manufacturing. SMA main strategy included joint ventures between the government and private sectors. By leveraging the expertise of partners, we can realize our ambitions. In this regard, we are happy to work with partners such as Maxis to achieve the common goal of utilizing the potential of innovative technology to improve the lives of people. Maxis launched the first commercial NB-IoT service in Malaysia in April 2019, with Kuching becoming one of the major IoT market centers through the activation of its NB-IoT network. The launch allows businesses to use industrial IoT applications to create new data streams, enabling action by connecting simple devices such as sensors. Meanwhile, Maxis continues to strengthen its presence in Sabah and Sarawak through the investment and expansion of mobile and high-speed fiber networks, as well as distribution and customer touch points (Bernama, 2019).

\section{MAXIS Provides High Speed Internet For UTAR Campus}

Maxis Bhd is working with Tunku Abdul Rahman University (UTAR) to provide high speed internet services for the university's two campuses in Sungai Long and Kampar. In a statement today, Maxis said, through this collaboration, each campus will be equipped with $1 \mathrm{Gbps}$ internet fiber access with inter-campus connection, as well as the latest Maxis Internet Protocol Metro Area Network (IPMAN). This has enabled the campus to increase the smoothness of broadband to high-speed internet when it is available in the future, adding that the campus will also enjoy high-speed mobile connections using the fastest 4G LTE network in the country. Maxis Chief Business Officer said the company was happy to work with UTAR to provide its students with the high-speed internet fiber developed by Maxis, as well as the 'always On' mobile connection. The Internet has become very important in our lives, and 
especially for students, important for academic activities, administration and way of life, and this is an important capability in the management of high data usage commonly seen today (Bernama, 2019)

\section{Movement Control Order (MCO) Shifts Virtual Education Method}

Smartphones are seen among the learning aids along the Covid-19. However, many students and students from low-income families (B40) are unable to have it due to family hardship. However, a foundation intends to provide the facility for free, including being equipped with a prepaid card and a 120GB data plan for a year to the group for learning purposes.

This contribution is positive and it is a proactive step in helping students and students who are less able to continue learning at home. The pandemic caused the educational institutions to close but learning continued at home. The contribution to these B40 students and students needs to be accelerated. Should, at the end of the first or second week of the Movement Control Order (MCO) be implemented, there are organizations such as non-governmental organizations (NGOs) or foundations to take immediate action to ensure that students can continue learning at home. The majority of students in the city do not face the problem of using smartphones as a learning aid. However, this opportunity is not enjoyed by B40 students and students especially in the suburbs, rural and inland, due to family economic factors. Not only that, the results of our interview study found that the parents of this B40 group do not know how to handle their children's learning at home during MCO. Smartphones are learning tools, but most importantly, after receiving these devices, can students and students access the Internet in their homes? Is it possible for students to be warm-hearted chicken poop to learn after being given a smartphone? People always see donations in helping the B40 group as an incentive that can change their lives for the better. People do not feel this scenario (warm chicken poop) happens because in fact, it is more towards the stigma of society. Stigma like this can stifle the good intentions of many parties to come forward to contribute to help students and B40 students to succeed in learning. Most important at this point is that it is not only focused on educating children, but also parents need to master the application on the smartphone. This is a challenging task. The latest data is needed to ensure that those who qualify are not dropped out. In addition, it needs to be implemented in stages. Thus, the agreement between parents and the school plays an important role to ensure that the selected qualified people become recipients. However, the middle income group (M40) is also eligible to be the recipient because they have a large number of children and the wife is not working. Of course this family (M40) could not provide a smartphone for all their children. They share using smartphones and this to some extent interferes with the online learning process (Zuraidah, 2020).

For now, it can say that most Malaysian students, teachers and parents are not fully prepared to use virtual learning methods. This virtual learning method is currently only at a moderately satisfactory level. This is due to the current situation especially in terms of infrastructure facilities (computers, laptops, tabs and smartphones) as well as Internet access. Although the Ministry of Education Malaysia (MOE) has trained teachers with various online learning methods, but this method is only as a tool or teaching aid for teachers. So far, teachers have been given the option to apply virtual learning methods. Plus, before this we did not focus seriously on virtual learning methods. Currently, teacher creativity is needed to ensure that online learning is implemented more effectively throughout MCO. It is now the main medium of student and student learning. Teachers need to have careful planning including sharing with other colleagues in providing learning modules and scheduling before implementing online learning. Through this partnership, teachers can improve their pedagogical skills, information technology and most importantly online assessment. This situation gives a new phenomenon in the learning of students and students that is their learning is not according to real time in school. It is more flexible, not only using Google Classroom, but can also apply various applications such as Google Meet, Microsoft Team, Zoom, Telegram and WhatsApp. I believe, the spread of Covid-19 at this time to force the government to implement MCO is the starting point for major changes in the Malaysian education system. Therefore, parents and teachers need to make a paradigm shift to master the latest information technology knowledge to address this problem. Smartphones are just learning aids to ensure that children can continue their learning while at home. The question that arises is, is the school ready to continue the virtual learning method and how to evaluate the learning of students and students more effectively. Do recipients need to have certain criteria to prevent donations from being misused? 
There are actually no specific criteria. All students who have been categorized as B40 are eligible to receive it. Owning this smartphone can be a motivator for students to learn more diligently. All can say is that the contribution of smartphones can increase their motivation to learn but provided Internet access is enhanced in all urban, rural and rural areas. If Internet access is not improved, it will be difficult for them to use the smartphone. In terms of quality, how to ensure a quality contributed smartphone? Indeed, this contribution is the corporate social responsibility (CSR) of the relevant parties. However, contributors need to ensure that the smartphone is quality and up-to-date. Society want students to be able to use these donated devices optimally and for a long period of time. At the same time, there should be staff for the purpose of monitoring and repairing damaged devices. The B40s do not have a lot of funds and are of course burdened to make smartphone repair costs which may cost a lot. This may cause them to take the easy way out of not fixing it and eventually it affects the children's learning process. As Malaysians, society should not depend entirely on the government, but need to think, what contribution can be given to the country, especially in the current critical situation (Zuraidah, 2020).

\section{Learning Ideas Using Model 5E Constructivism}

Learning during the Movement Control Command (MCO) is very different if compared to learning during regular teaching in the classroom. Many planned activities could not be carried out due to the constraints of physical imprisonment given priority. However, the post-pandemic teaching of Covid-19 must be more creative so that students do not miss out on this epidemic. Follow the partnership of three post-independence teachers from Danau Kota Primary School (2), Kuala Lumpur, who integrated Model 5E with Covid-19 post-pandemic teaching especially for primary school teachers (Roshlawaty, 2020).

The use of the 5E Model based on the constructivist approach is a very significant smart move in impacting learning in the classroom. 1) Phase 1: Engage. The teacher informs the subtopic students that will be learned in the next lesson. Pupils use the opportunity at home to get a glimpse of the subtopics to be learned. 2) Phase 2: Explore. Pupils explore learning content and search the internet or use the Youtube site to understand the content of the lesson to be learned. All questions or things that are not understood will be recorded in a notebook. 3) Phase 3: Explain. While at school, the teacher will explain the content of the lesson and the students will relate to the content of the lesson they have learned at home. 4) Phase 4: Elaborate. The teacher will explain all the questions that are not understood by the students as the students have recorded all the questions in the notebook and take advantage of the opportunity to face the teacher at school to get an explanation for a topic that is not yet well mastered. 5) Phase 5: Evaluate. The assessment process aims to test the understanding of students and teachers will provide quizzes through various mediums such as Google Classroom or through interesting interactive games such as 'wordwall', 'liveworksheet' and so on (Roshlawaty, 2020).

Model 5E allows a teacher to provide training based on their creativity. Whether they want to provide training in the classroom or take advantage of the latest technology by providing training or quizzes through the Google Classroom site owned by every student in the school. Online sites such as liveworksheets, wordwall and so on are examples that can be utilized for the use of students. All this depends on the level of internet access of students at home and this situation can certainly form a very holistic learning scope in the daily life of students at home. The message of these three great teachers again, learning is an element that always happens throughout life and not just tied up in school alone. Therefore, utilizing the Model $5 \mathrm{E}$ is a very significant step in giving maximum impact to teachers in schools (Roshlawaty, 2020).

\section{E Online Learning Model}

$5 \mathrm{E}$ is an instructional model based on a constructivism approach to learning. This model states that students construct new ideas based on their old ideas. This 5E approach is also suitable for students of all ages, including adults. Each $\mathrm{E}$ in the $5 \mathrm{E}$ tells about the learning phase. Starting with Engage, Explore, Explain, Elaborate and even Evaluate. This 5E method allows students and teachers to 
experience familiar activities, using basic knowledge, to form meals and ultimately increase understanding of concepts continuously (Norhailmi, 2017).

ENGAGE (Engagement)

- introduce context

- provide situations for learning episodes

- provides relevance to learning - encourage curiosity about 'the big idea'

- encourage students to give early ideas

- know the students' existing understanding and detect misconceptions

- allows teachers to know how to begin the development of student understanding

\section{EXPLORE}

- most important E

- students build understanding of concepts based on first-hand experience

- start answering the questions posed

- in exploration, students can be guided or given additional information to facilitate learning

- importantly, students need to have ownership

- students can build understanding from their existing ideas

EXPLAIN (Description)

- this stage requires input from the teacher after the student builds an understanding of the concept, this involves strengthening in terms of terminology, definitions, models and analogies - teachers need to involve students in making explanations and further construction of ideas through reflection on what students have encountered in exploration using questions

- if necessary, teachers can add new ideas with level repetition: exploration -> explanation

-> exploration -> explanation

\section{ELABORATE (Processing)}

- strengthen, deepen and develop understanding of concepts by applying the concept

- students are given problems to solve to understand how big ideas are practiced

EVALUATE (Rating)

- assessment through various methods and tasks

- should be done at the end of each $\mathrm{E}$ to check the development of student understanding that is formative assessment

- when the assessment is done at the end of each unit then it is in the form of summative to measure student achievement

\section{Online Application of Constructivism Theory}

Nowadays, the teaching and learning process involves a lot of online learning. Online learning is when the content of learning materials presented online and the learning activities themselves such as obtaining information are also done online. Online learning can involve the use of various multimedia applications for the process of presenting information to students. This is in line with the ministry's intention, which states that the school curriculum should be formulated so that students can select, analyze and evaluate information using technology effectively. Web-based learning is an alternative approach that has many advantages and in turn has the potential to improve the quality of the teaching and learning process. This is because, the physical features of the website such as attractive interface as well as the ability to integrate various multimedia elements make this learning method different from conventional learning methods. The interactive features found in this online learning enable to increase students learning interest (Noor Dayana, Mohamad Bilal \& Juhazren, 2012). When educators intend to design a medium or learning material, there are various aspects that need to be emphasized so that the material produced can meet the learning needs as well as meet the needs of students. The application of learning theory in designing learning materials such as multimedia software and websites should be given in-depth emphasis. In addition, the motivation component is also seen as one of the important aspects in order to attract students while using a learning material. 
Constructivist learning theory places more emphasis on student activities. The main focus of this theory is on the mental activity of the students, not on the behavior. Learning from the perspective of constructivism is seen as a process in which the experience he goes through and relates to knowledge. During teaching and learning, each individual actively builds their knowledge, rather than passively receiving that knowledge from others. In general, the constructivist approach has had an impact on the R\&D process. This is because in applying this approach, students are exposed to complex activities such as making connections, reflecting, asking and answering questions, elaborating on the content of the lesson, discussing, inquiring, solving problems constructing ideas, analyzing, and synthesizing ideas. Compared to objectivism approach, the implementation of constructivist learning has various advantages. Among the benefits is that students will be more confident, more thinking, more remembering, more understanding, more socially skilled and more fun. In addition, various other advantages use this approach. The first is the effect on students' thinking. When students think to solve a given problem, students will achieve a higher level of thinking than students who only receive knowledge wholeheartedly without thinking. Second, students will be more positive because student involvement is active and maximum to form knowledge. Students have the opportunity to interact twoway with other teachers and friends. Finally, constructivism will promote lifelong learning. This is because students will be trained to obtain information by solving the problems that occur around them (Noor Dayana, Mohamad Bilal \& Juhazren, 2012).

\section{Motivation is Important in Online Learning}

While it not the intention here to supply a comprehensive review of the history of distance education, or the place of online learning within it, it's important to debate two theoretical concepts that are influential within the overall development of the sector and still influence our understanding of learning and motivation in contemporary online contexts. These concepts are transactional distance that encompasses the notions of structure, dialogue and autonomy; and therefore the alternative concept of learner control. Similar concepts exist within contemporary motivation literature, particularly those related to self-determination theory - the motivational framework that underpins this investigation (Hartnett, 2016).

The term "transaction distance" to determine the psychological separation that students often experience, which is the spatial and/or temporal separation between students and educators in the context of distance learning. From this perspective, the structure and the relative number of dialogues that exist in learning activities determine the level of "distance" that students experience. Structure refers to curriculum design and points out the flexibility or rigidity of teaching methods, goals, and assessment practices. Dialogue refers to the degree of interaction with the lecturer and is related to the media. Dialogue and low structure equals high transaction distance, and vice versa. However, theory suggests that it is difficult to achieve both a high level of dialogue and structure at the same time. The theory also covers the third concept, student autonomy. The greater the transaction distance (i.e. low structure and dialogue), the greater the responsibility to students. In this model, autonomy is related to freedom and self-learning. Although Moore pointed out that the transaction distance model does not mean that autonomous students do not need teachers, he does show that they need fewer dialogues and minimal structure than autonomous students.

The term "autonomy" lacks a clear definition. The concept of student control is a richer and more inclusive concept because it helps overcome the confusion related to the role of freedom in distance education. In this conceptualization, control is related to the opportunity and ability to influence, direct, and determine decisions related to the educational process. This can only be achieved by striking a balance between freedom (free choice without restriction or outside influence). Power-later called ability-(the ability to be responsible for and participate in the learning process); and support (to provide students with resources including teachers throughout the learning process). In this mode, the teacher's support can enhance the control of the students; it does not take its roots. It is tested the model through validation factor analysis and found that the next three main factors reflect the recommended size. The work of other researchers has also affected our understanding of choice, control, and autonomy in distance education. Focuses on self-direction and distinguishes two types: self-direction is 1) personal 
characteristics; 2) the level of control that students have when determining the learning path. This is an important difference because it is aware that autonomy is a variable of individuals and circumstances. In other words, the degree of autonomy a person expresses may vary from situation to situation. Previous theoretical works developed a conceptual model called transaction control. Transaction control is related to choice and effort to explain the dynamics of transaction distance. In this model, the structure is equivalent to teacher control, dialogue related to negotiation control, and autonomy related to student control. In other words, control is seen as a continuum from student control at one end to teacher control at the other end, which is determined by choices made along the learning path. Although the concepts of autonomy, freedom, control and agency are essential to the development of distance education theories, other theories are also influential (Hartnett, 2016).

\section{Parents Welcome Online Teaching And Learning}

Online teaching and learning methods are now an alternative following the closure of schools due to the Movement Control Order (MCO) which is still in force. Its implementation received positive feedback from parents but problems arose especially for a handful of pupils and students who do not have the device or Internet access to apply online teaching and learning at home. This method should be done earlier for example for students who cannot attend school due to illness or others but it is not too late to implement only a problem for a few teachers or parents who are less skilled in using certain applications online. In addition, there are also barriers for pupils or students who do not have an electronic device or it is available but limited and no Internet access. In this regard, teachers need to work hard to find ways how to provide learning materials especially in helping students or underprivileged students not to be left behind during the MCO period (Redzuan, 2020).

Teaching and learning methods are interesting because they run away from the norm but the government is expected to find alternatives to help students in rural areas so that they are not left behind just because there is no Internet access. Meanwhile, teachers need to diversify teaching and learning methods without focusing on the distribution of school work that requires pupils or students to write alone. In terms of convenience, pupils or students may be able to use their parent's smartphone only a problem for those who do not have Internet access or limited devices due to the number of children. Teachers can make a difference through exercises in the form of quizzes for specific subjects to attract students to learn even when at home. To date, no complaints have been received from parents regarding teaching and learning during the $\mathrm{MCO}$ and even teachers have cooperated well. However, the number of daily subjects for teaching and learning during MCO time was reviewed to make it easier for parents to monitor their children. One or two subjects is enough and not on a schedule like in school because not all parents have good device facilities (Redzuan, 2020).

\section{ICT Improves Thinking Skills}

The use of Information and Communication Technology (ICT) in teaching and learning is able to create a realistic, interactive and fun environment. Through ICT, students are able to generate creativity and innovation, as well as efficiently use technology to access information from various sources in line with global developments based on e-learning and k-economy. Among the use of ICT in the teaching and learning process are tutorial learning, application exploration and communication. As a result, students who are in the classroom are able to communicate up to the global level either bilaterally or more. The teaching and learning environment also becomes more interesting through the use of ICT elements such as text, audio, video, graphics and animation that can improve the level of thinking and communication skills to solve problems, then make decisions. The sustainable use of ICT in a planned, appropriate and thoughtful manner is very necessary to improve process efficiency and effectiveness of teaching and learning. It is one of the integrated efforts that need to be implemented immediately to enhance the ability of ICT -integrated teaching and learning in line with current educational needs. Once upon a time, humans did not even think to learn or teach using this method (ICT). But now, it is awkward if we do not use this method. Time has changed. ICT is no longer a side need but a priority to support the process to make teaching and learning easier and more effective (Ruhaiza, 2016). 
Although some people think that ICT may cause a clash with conventional teaching and learning methods, but if balanced well, the results obtained are quite worthwhile. Both methods have their advantages and disadvantages and should not be debated. While there are shortcomings in conventional teaching and learning such as being more instructor-centered and more one -way communication, it is still relevant. This method is very effective in giving understanding to students at the beginning of learning. Learning based on Blended Learning Mode with teaching and learning process combining conventional methods and online learning. ICT integration can complement or strengthen existing teaching and learning without marginalizing previously used methods. The use of ICT can help improve student achievement, because students come from a variety of educational backgrounds and need to master many facts and theories, the use of such technology is able to help them. Students' mastery can be enhanced by integrating ICT in teaching and learning such as the use of interactive multimedia websites that display lesson content. This material can be used as additional material to reference books while the multimedia elements used are proven to be able to increase motivation and inclination to learn. Students not only scored high in exams, but their level of understanding and appreciation was also stronger. For example, quizzes or online exercises can help students improve achievement in a subject because it can be done at any time and place. Students can measure their achievement easily while instructors can monitor and analyze the level of student achievement. Through the use of the Online Teaching Assessment system, instructors can also find out their achievements, thus helping them improve the way they deliver. Advances in technology not only affect teaching and learning, but also performance training and knowledge building. Among them, the emergence of borderless schools and campusless institutions of higher learning that share resources and employment through technology. There is now an ICT -integrated R\&D policy, but there is still a gap that needs to be improved between urban and rural areas. In this regard, the implementation of the National Broadband (NBI) initiative launched by the Communications and Multimedia Commission (MCMC) since 2007 has greatly improved access to information. Many efforts have been made for this purpose, thus showing that Malaysia is ready to implement technology -based teaching and learning. On the positive impact following the use of teaching and learning by teachers and students, among them is able to facilitate understanding and interest, more creative and motivational, facilitate discussion and save time. However, do not forget the negative impact. Among them are students skipping lectures because the notes have been uploaded in the e-learning system apart from the lack of communication between students and instructors (Ruhaiza, 2016).

\section{Conclusion}

The Ministry of Education Malaysia (MOE) is confident in the ability and creativity of teachers in determining the best method to ensure the teaching and learning process at home during the period of the Movement Control Order (MCO) runs smoothly. Teachers have also been reminded to take into account every constraint faced by students at home and then set the appropriate method for teaching and learning at home. Issues were faced and matters were raised and even parents and teachers faced pressure following the implementation of online classes. In the guidelines given at the beginning of the MCO period of the day already stated the basic principle is to take into account the constraints faced by teachers and students. The ministry has conducted a survey of more than 670,000 parents and nearly 900,000 pupils and students to get feedback. The results of the survey found that the ownership of electronic devices to enable MCO to be implemented at home is quite limited. Of the 900,000, only six percent own a computer while another 5.76 percent own a tablet. Meanwhile, another nine percent own a laptop, 45 percent a smartphone and 36.9 percent do not have any device at home. In this context, MCO at home is a challenge especially for children who do not have a device and slow internet access will take a long time. Regarding the ministry's initiative to introduce Education Television (DidikTV) during the MCO starting 16 Feb 2021, the Ministry will continue to improve in ensuring that pupils and students benefit while undergoing $\mathrm{MCO}$ at home. 


\section{References}

Bernama. (2019). MAXIS Provides High Speed Internet For Tunku Abdul Rahman University Campus (UTAR). Kuala Lumpur: Bernama.

Bernama. (2019). Maxis, Sarawak Multimedia Authority (SMA) collaborates in IoT initiatives. Maxis Bhd MoU signing ceremony with Sarawak Multimedia Authority (SMA). Kuala Lumpur: Bernama.

Che Wan Badrul Alias. (2016). Samsung, LG Introduce Virtual Reality Smartphones. Kuala Lumpur: Mobile World Congress.

Che Wan Badrul Alias. (2019). Maxis Explores Digital Gaming Industry Opportunities. Kuala Lumpur: Maxis.

Hartnett, M. K. (2016). The Importance of Motivation in Online Learning. New Zealand: Massey University.

Hawati Abdul Hamid and Jarud Romadan Khalidi. (2020). Bridging The Digital Divide Prevents Students From Dropping Out. Kuala Lumpur: Khazanah Research Institute.

Mohd Nasaruddin Parzi. (2019). MOJO Nurtures Creative, Innovative Content. Kuala Lumpur: Ministry of Multimedia and Communication.

Mohd Zaky Zainuddin. (2020). COVID-19: Maxis Records The Use Of Additional Data In History. Kuala Lumpur: Maxis Bhd.

Muhammad Yusri Muzamir. (2021). Internet Access, Less Gadgets Can Make Teaching And Learning At Home Difficult. Kuala Lumpur: New Strait Times Press.

Noor Ayuni Che Zakaria. (2020). Online Lectures To Avoid Infection. Shah Alam: Faculty of Mechanical Engineering, MARA University of Technology (UiTM).

Noor Dayana Abd Halim, Mohamad Bilal Ali \& Juhazren Junaidi. (2012). Application of Constructivism Theory and ARCS Motivation Model in Acid-Based Learning and WebsiteBased Basics. Skudai: University of Technology Malaysia.

Norhailmi bin Abdul Mutalib. (2017). 5E Online Learning Model. Kuala Lumpur: Cikgu Hailmi.com.

Ong Yao Ping. 2020. Teachers Need To Master Digital Technology To Meet The Demands Of Teaching And Learning. Sintok: Universiti Utara Malaysia.

Radzi Jidin. (2020). Parliament: Ministry of Education Malaysia Detects 763 Schools Have Covid-19 Cases. Kuala Lumpur: Ministry of Education Malaysia.

Redzuan Muharam. (2020). Parents Welcome Online Teaching And Learning. Kuala Lumpur: Daily Metro.

Roshlawaty Raieh. (2020). Three Young Teachers Share 'Learning Ideas' Using Model 5E Constructivism. Kuala Lumpur: GPS Bestari.

Ruhaiza Rusmin. (2016). ICT Improves Thinking Skills. Kuala Lumpur: Daily Metro.

Shamsul Arrieya Ariffin. (2016). Smart Learning Boosts Student Activity. Kuala Lumpur: Department of Computer, Faculty of Arts, Computers, and Creative Industries, Sultan Idris University of Education.

Sri Ayu Kartika Amri. (2018). The New MaxisONE Prime Came With Unlimited Data. Kuala Lumpur: Maxis Bhd.

Zuraidah Abdullah. (2020). Movement Control Order (MCO) Shifts Virtual Education Method. Kuala Lumpur: University of Malaya. 